$$
\begin{array}{cl}
\text { Pyrotraubensiuure } & \text { Milchsäure } \\
\mathrm{C}^{6} \mathrm{H}^{4} \mathrm{O}^{6} & \mathrm{C}^{6} \mathrm{H}^{6} \mathrm{O}^{6} .
\end{array}
$$

J. Wislicenus fand, dass sich in der That nach dem bekannten Verfahren der Wasserstoffaddition durch Natriumamalgam und Wasser die Pyrotraubensäure in Milchsäure verwandeln lässt. Nimmt man auf ein Molecül der Säure etwas mehr als 2 At. Natriumamalgam, so geht die Reaction unter zuletzt auftretender Entwickelung von Wasserstoffgas leicht von statten und der mit Salzsäure versetzte und auf dem Wasserbade eingedampfte Rückstand giebt beim Ausziehen mit Aether eine Lösung, welche mit gewöhnlicher Milchsäure vollkommen identische Milchsäure enthält.

Leitet man Jodwasserstoffgas in Pyrotraubensäure, so entsteht aus letzterer Propionsäure, indem von 4 Molecailen Jodwasserstoff zwei reducirend, die beiden anderen Wasserstoff addirend wirken.

$$
\mathrm{C}^{6} \mathrm{H}^{4} \mathrm{O}^{6}+4 \mathrm{HJ}=\mathrm{C}^{6} \mathrm{H}^{6} \mathrm{O}^{4}+2 \mathrm{HO}^{-4} \mathrm{~J} .
$$

Ebenso wird Propionsäure erzeugt, wenn man Zweifach--Jodphosphor und Pyrotraubensäure zu gleichen Molecülen anwendet. Nimmt man dagegen auf 3 Molecüle der Säure nur 1 Moleciul Zweifach-Jodphosphor, so resultirt wieder Milchsäure und der Process verläuft nach der Gleichung:

$$
\mathrm{C}^{6} \mathrm{H}^{4} \mathrm{O}^{6}+2 \mathrm{HJ}=\mathrm{C}^{6} \mathrm{H}^{6} \mathrm{O}^{6}+\mathrm{J}^{2} .
$$

(Ann. der Chem. u. Pharn. (XXVI. 22.5-239.) G.

\title{
Darstellung der citronensauren Magnesia;
}

$$
\text { von de Litter. }
$$

Zur Darstellung eines in kaltem Wasser völlig löslichen Magnesiacitrats, welches diese Eigenschaft auch behält, nimmt man:

$$
\begin{array}{ll}
\text { Citronensäure } & 20 \\
\text { Weisse Magnesia } & 12 .
\end{array}
$$

Die Säure wird gepulvert und mit der Magnesia innig gemischt. Die Mischung lässt man 4-5 Tage bei gewöhnlicher Temperatur stehen oder so lange, bis man fast keine Reaction mehr beim Werfen in Wasser bemerkt. Während der gegenseitigen Einwirkung bläht das Pulver sich auf und nimmt nach und nach das Aussehen eines Schwammes an. Man trocknet es bei etwa $30^{\circ} \mathrm{C}$., pulverisirt es und bewahrt es in gut verschlossenen Gefässen auf.

Die Abwesenheit des Wassers bei der Darstellung 
ist von Wichtigkeit, da dessen Gegenwart den allmäligen Uebergang des Salzes in die unlösliche Modification anbahnt. (Journ. de Pharm. et de Chim. Mai 1863.)

Dr. Reich.

\section{Citronensaure Bisenoxyd-Magnesia}

stellt man auf die Weise dar, dass man in einer Lösung von 3 Unzen Citronensäure das aus $31 / 4$ Unze schwefelsaurem Eisenoxydul erhaltene Eisenoxydhydrat auflöst, die Flüssigkeit dann mit kohlensaurer Magnesia săttigt, filtrirt und abdampft. Hat die Masse Extractconsistenz, so streicht man sie dünn auf Glasplatten und trocknet sie dann. (Pharm. Journ. and Transact. Jan. 1863. p.329.)

H. F.

\section{Umwandlung der Aconitsãure durch Natriumamalgam.}

Kekulé hat gezeigt, dass sich die Itacon- und die Citraconsäure in Berührung mit Natriunamalgam ohne Entwickelung von Wasserstoffgas direct mit dem Metalle verbinden und in Pyroweinsaure übergehen; und dass unter gleichen Umständen die mit jenen homologe Fumar- und Aepfelsäure Bernsteinsäure geben. Des saignes hat vor einigen Jahren gezeigt, dass die Aconitsüure, welche, wenn nan sie zweibasisch annimmt, mit der Fumar- und der Aepfelsäure isomer ist, durch Gährung ebenfalls in Bernsteinsäure umgewandelt wird! Es fragt sich nur, ob sie auch durch Natriumamalgam die gleiche Umwandlung orleidet. Zuerst scheint dies nicht so zu sein, denn wenn man eine Lösung der Säure mit dem Amalgam versetzt, so entsteht ein lebhaftes Aufbrausen, welches schwächer wird, wenn die Säure gesättigt ist. Die Reaction wurde mehrere Tage hindurch fortgesetzt, indem man von Zeit zu Zeit einige Tropfen, zuletzt einen grösseren Ueberschuss von Salzsäure hinzufügte, den Rüickstand mit Alkohol erschöpfte, diesen im Wasserbade entfernte und den neuen Rückstand mit Aether behandelte. Dessaignes erhielt auf diese Weise eine Säure, welche weder Aconit. noch Bernsteinsäure war, obgleich sie diesen beiden und rorzüglich der letzteren sehr nahe kam. Sie ist in Wasser löslicher als Aconitsäure, krystallisirt in strahlenformig angeordneten Krystallen, welche grösser als die der Aconitsïure sind, schmilzt bei $155^{\circ}$ und färbt sich erst über $200^{\circ}$; im Röhrchen schnell erhitzt, giebt sie ein weisses Sublimat und hinterlässt keinen Rück- 